\title{
Study on Institutional Guarantee and Government Responsibility for the Development of Preschool Education Cause
}

\author{
Geping Han \\ Ankang University, Ankang, 725000, China
}

\begin{abstract}
Keywords: preschool education, institutional guarantee, government responsibility
\end{abstract}
\begin{abstract}
Preschool education legal system is a powerful guarantee for promoting the development of preschool education cause. With the continuous development of social economy, preschool education has many new situations and problems. To solve these problems effectively, we shall establish a sound preschool education institutional guarantee system, and give full play to the leading role of government, so that work of preschool education can be carried out by following laws and regulations. This paper studies on the current situation of institutional guarantee for the development of preschool education cause and responsibilities that government shall assume.
\end{abstract}

\section{Importance of preschool education institutional guarantee}

(1) Conducive to promoting sustainable development of China's preschool education cause

In recent years, the amount and scale of China's preschool education increase constantly. However, due to lack of a sound institutional guarantee system, kindergartens in different regions have uneven schooling level and teachers. In particular, rural preschool education is obviously backward compared with the development of urban preschool education. Meanwhile, private kindergartens have problems such as arbitrary charges and chaotic management etc, which seriously restrict sustainable development of China's preschool education cause. Thus, China shall perfect preschool education institutional guarantee system, give full play to the leading role of government, make clear of the government's responsibilities and obligations, support preschool education to the greatest degree, maintain public interest and balance of preschool education, and promote rapid and steady development of preschool education.

(2) Conducive to perfecting China's education legal system

A sound education legal system is the premise and foundation of improving a country's overall educational level. At present, China has issued and implemented Education Law, Compulsory Education Law, Higher Education Law and other education legal documents. However, as there is not legislation of preschool education, China shall accelerate legislation of preschool education, make clear of rights and obligations of the government, kindergartens and teachers, and provide legal guarantee for the development of preschool education cause.

(3) Conducive to meeting high requirements of the masses for preschool education

The establishment of China's preschool education system shall take actual demands of the masses for preschool education as the fundamental starting point and foothold, improve constantly the quality and level of preschool education, and give full play to the important role of preschool education in promoting healthy development of preschool children's mind and body. Thus, Chinese government shall strengthen the establishment of preschool education institutional guarantee system, change current situation of private kindergartens such as insufficient management, teachers' low qualities and shortage of education funds, include preschool education into legal institution, and mobilize all social forces to participate in and manage preschool education.

(4) Conducive to promoting China's preschool education to be geared to international standards

At current stage, lots of developed countries have established a sound preschool education system guarantee system, standardize schooling pattern of preschool education by relying on institutional guarantee system, and ensure stable source of schooling funds. In particular, preschool education legislation of developed countries such as the United States, Japan, the UK and France etc holds a leading position in the world, and is also main object that legislation of China's preschool education shall learn from, in order to narrow the gap between China's preschool education and preschool education in developed countries, and improve the international level of 
China’s preschool education.

\section{Current situation of institutional guarantee for the development of China's preschool education cause}

(1) Lack of special preschool education law

At present, China has not special legislation for preschool education, so that the development of preschool education cause lacks legal protection, which is also one of important factors that hinder the healthy development of preschool education cause. This is mainly reflected in the following three aspects: firstly, existing preschool educational laws and regulations have not made clear of the position of early education, have not sorted the relations between preschool education and the government, society and market, and thus early education cannot be guaranteed practically. Secondly, current preschool education laws and regulations have many imperfections, such as a lack of confirmation of the identity of preschool teachers, no guarantee for due treatment of preschool teachers, and no clear source of financial funds of kindergartens etc. Thirdly, laws and regulations of preschool education lack integrity and unity, and are still in a low legal level, are difficult to provide legal basis for preschool education, and are not conducive to improving social concern for preschool education.

(2) Lack of a guarantee system for funds of preschool education

In China's total education expenditure, preschool education funds have been occupying a small proportion, less than $1.5 \%$, resulting in a serious lack of preschool education funds. Meanwhile, China does not have separate financial education budget for preschool education, and provinces, cities and counties rarely input financial funds for preschool education. Particularly, under the heavy pressure of nine-year compulsory education, all levels of governments have a serious lack of education funds, so that preschool education funds are often used in compulsory education. In this case, as preschool education lacks financial funds from the government and has not a funds source guarantee system to rely on, difficulty in carrying out preschool education is thus increased.

(3) Lack of preschool education administrative management mechanism

Currently, China's administrative department of preschool education has not a sound management mechanism and has quite weak management strength. With continuous development of China's education cause, to save educational resources, most provinces and cities have cancelled and merged preschool education administrative management department, and have not equipped special management personnel for preschool education management. With a lack of administrative management, it is very difficult to solve new problems and situations occurred in preschool education effectively, so that preschool education cannot adapt to complex development situation of China's education cause, which is not conducive to steady enhancement of the quality of preschool education.

(4) Lack of a preschool education teachers building guarantee system

In recent years, China's preschool teacher building has made some achievements, and the number of preschool teachers increases year by year, and thus could meet demands of China's preschool education for the number of preschool teachers. However, preschool teachers generally have problems such as low overall qualities, uneven quality and imperfect training mechanism etc, coupled with uncertain status and generally low treatment level, and preschool teachers are unstable, which is not conducive to promoting sustainable development of preschool education cause. In addition, some kindergartens with non-standard management even have disgusting conducts such as violence of preschool teachers etc, which seriously affect healthy development of preschool children's mind and body.

\section{Responsibilities that the government shall assume in the development of preschool education cause}

(1) Carry out legislation of preschool education

All levels of governments shall accelerate legislation of preschool education, guarantee healthy 
and sustainable development of preschool education cause by laws, make clear of responsibilities that the government shall assume in laws, and make preschool education more legal and standard. Firstly, establish value orientation of preschool education legislation. Preschool education legislation shall follow concepts of fair education and lifelong education in education legislation, take such concepts as basic value orientation of preschool education legislation, reflect the aim of equal educational services fully, and make rural and urban children enjoy equal right to receive education. Secondly, issue special law of preschool education. Education legislation is an important way for the government to fulfill educational responsibilities. At present, China has quite sound legislation in terms of higher education and compulsory education, while legislation of preschool education is at the initial stage. Although China has issued Kindergarten Management Regulations, Guidelines for Kindergarten Education (Trial), Guidelines for National Medium and Long-term Educational Development Planning and other legal documents in recent years, these documents are only for lower-level preschool education, and still fail to guarantee the important position and role of preschool education in China's education system. To this end, the government shall formulate special education law for preschool education, make clear of government's due responsibilities in preschool education, guarantee the importance degree of all levels of government for preschool education by law, get rid of the situation of overdependence of kindergarten schooling on social forces completely, and improve the current situation of chaotic management of preschool educational institutions.

(2) Perfect preschool education input guarantee mechanism

To guarantee sustainable development of preschool education cause, the government shall assume responsibilities of financial input and resource allocation, build a sound preschool education input guarantee mechanism, and make various input work achieve orderly development. Specific practices are as follows: firstly, the government shall formulate preschool education prior development strategy, allocate preschool education funds separately and include into public financial budget, make education funds incline to preschool education gradually, and thus relieve problems of expensive and difficult kindergarten admission. Secondly, the government shall formulate preschool education financial allocation standard in terms of policy, take preschool education of central and western rural areas as the focus of financial support, promote the development of rural preschool education cause vigorously, and narrow the gap between urban and rural preschool education, so as to promote balanced development of China's preschool education. Thirdly, the government shall introduce social funds rationally, advocate actively social forces to donate for kindergartens, and form new schooling mechanisms of combination of private and public kindergartens, separation of management from schooling, assistance of financial and private funds, common supervision of the government and society. The government shall play a full leading role in new schooling mechanism, guarantee public interest of preschool education, sort the relation between the government and kindergartens, regulate social schooling behaviors, create a fair, just and transparent preschool education environment, and ensure equal opportunities and social welfare of preschool education. Finally, the government shall strengthen supervision and management of various funds of preschool education, implement an accountability system for preschool education funds expenditure, and increase utilization benefits of education funds. Meanwhile, the government shall also optimize allocation of preschool educational resources, and establish a preschool educational service costs mechanism shared jointly by the government, society and families, in order to allocate preschool educational costs rationally.

(3) Build a preschool education administrative management mechanism

Government is the responsible subject of preschool education, and shall assume actively main responsibilities of the development of preschool education, highlight management functions of education departments, and establish a sound administrative management mechanism that is in line with the development of preschool education. Firstly, establish a government-led preschool education public governance mechanism with joint participation of society and market, advocate a diversified schooling form actively, and make full use of social educational resources. The government shall guarantee public interests of preschool education, build an operating schooling 
mechanism of social forces, make private and public kindergartens have equal position in terms of registration examination and approval, teacher training, classification and grading, commendation and awards, and professional title appraisal etc, and strengthen supervision of private kindergartens, regulate schooling behaviors, and improve schooling quality. Secondly, the government shall strengthen the functions of education departments in preschool education management, set special preschool education administrative management institutions, allocate full-time management personnel, perfect preschool education classification management, registration management and charge management system, and ensure reasonable implementation of various management systems and management measures. In particular, it shall attach importance to management of educational activities of private kindergartens, supervise private kindergartens to declare charge items according to relevant provisions, implement cost accounting, and avoid arbitrary charge of private kindergartens.

(4) Strengthen building of preschool teachers by various measures

The key of development of preschool education cause lies in preschool teachers with enough number, balanced structure, high quality and orderly management, so that preschool teachers could be fully devoted to preschool education cause. Only in this way, can powerful guarantee be provided for sustainable development of preschool education. Thus, the government shall take more measures simultaneously, strengthen the building of preschool teachers, and comprehensively improve overall qualities of preschool teachers. Firstly, all levels of governments shall formulate preschool teacher training policy, build a training mechanism, provide opportunities for in-service preschool teachers to receive training, and guarantee orderly operation of preschool teacher training mechanism through relevant system. In training, take improving professional qualities and moral qualities of preschool teachers as core tasks, so that preschool teachers could master scientific preschool educational concepts and methods, enhance their sense of responsibility and attach importance to healthy development of preschool children's mind and body. Secondly, perfect preschool teacher access system and appointment system. China shall refer to successful experience of developed countries in preschool education, introduce properly preschool teacher qualification recognition mechanism and access mechanism, control the quality of preschool teachers from the source, restrict people with poor professional quality from being preschool teachers, and ensure preschool teachers to pass qualification accreditation of relevant national departments. Finally, improve the treatment level of preschool teachers. Provisions of China's Teachers Law clearly point out that preschool teachers are members of primary and secondary teachers. However, as China's current legislation of preschool education is still in the initial stage, preschool teachers have vague identity and status. Thus, China shall make clear of the identity and status of preschool teachers in terms of law, maintain basic rights and interests of preschool teachers, and give them due wage and treatment and social security, which mainly include endowment insurance, basic wage, retirement pension, medical insurance, and pension for the disabled or for the family of the deceased etc. By increasing treatment for preschool teachers, more excellent talents can be attracted to be devoted to preschool education cause, which plays an important role in stabilizing preschool teachers.

\section{Conclusions}

To sum up, establishment of a sound preschool education system guarantee system and full fulfillment of responsibilities of the government in preschool education are the only way to promote healthy and sustainable development of preschool education cause. Therefore, China shall make clear of the important position of preschool education in education system, perfect preschool education system constantly and improve the quality and level of preschool education by accelerating preschool education legislation and perfecting input guarantee mechanism, administrative management mechanism, and preschool teacher building mechanism etc.

\section{Acknowledgments}

This paper is phased research result of 2011 College Key Education and Teaching Reform 
Project "Establishment of Practical Teaching System for Newly Established Preschool Education Major in Undergraduate Colleges” (project No.: JGO4107) of Ankang University.

\section{References}

[1] Lu Ying. Study on Legislative Status and Development Concept of Current Chinese Preschool Education [D]. Harbin Normal University. 2012.

[2] Xu Jianping. On the Lack of Preschool Education Public Interest and Its Countermeasures-In the View of the Government's Duty [J]. Studies in Preschool Education. 2011 (2).

[3] Zhang Xianbing. Problems and Countermeasures of the Reform and Development of Our Country's Preschool Education under the Philosophy of Education of Esteem [J]. Journal of Northeast Normal University (Philosophy and Social Sciences). 2009 (5).

[4] Pang Lijuan. Main Problems, Challenges and Reform of Current Chinese Preschool Education Management System [J]. Studies in Preschool Education. 2013 (6).

[5] Pei Xinping. Government Dominance, Responsibility Strengthening, Institutional Innovation and Comprehensive Promotion-Study on the Development of Preschool Education Cause in Zhejiang Province [J]. Early Childhood Education. 2009 (3).

[6] Fan Mingli. Main Problems and Challenges Encountered in Current Chinese Preschool Education Management System [J]. Exploring Education Development. 2012 (2).

[7] Wang Lan. On Balanced Development of Preschool Education and Building of A Guarantee System [J]. Journal of Southwest Agricultural University (Social Science Edition). 2013 (1).

[8] Bai Tan. The Responsibility of Governments at All Levels in Improving the Development of Preschool Education: Reason, Question and Assume [J]. Education Research Monthly. 2013 (1). 